\title{
Asymptomatic malaria infections and Pfmdr1 mutations in an endemic area of Nigeria
}

\author{
Titilope M. Dokunmu', Cynthia U. Adjekukor', Omolara F. Yakubu', Adetutu O. Bello², Jarat O. Adekoya², \\ Olugbenga Akinola ${ }^{3}$, Emmanuel O. Amoo ${ }^{4}$ and Abiodun H. Adebayo ${ }^{1^{*}}$
}

\begin{abstract}
Background: Malaria eradication globally is yet to be achieved and transmission is sustained in many endemic countries. Plasmodium falciparum continues to develop resistance to currently available anti-malarial drugs, posing great problems for malaria elimination. This study evaluates the frequencies of asymptomatic infection and multidrug resistance-1 ( $m d r-1)$ gene mutations in parasite isolates, which form the basis for understanding persistently high incidence in South West, Nigeria.

Methods: A total of 535 individuals aged from 6 months were screened during the epidemiological survey evaluating asymptomatic transmission. Parasite prevalence was determined by histidine-rich protein II rapid detection kit (RDT) in healthy individuals. Plasmodium falciparum mdr-1 gene mutations were detected by polymerase chain reaction (PCR) followed by restriction enzyme digest and electrophoresis to determine polymorphism in parasite isolates. Sequencing was done to confirm polymorphism. Proportions were compared using Chi-square test at $\mathrm{p}$ value $<0.05$.

Results: Malaria parasites were detected by RDT in 204 (38.1\%) individuals. Asymptomatic infection was detected in 117 (57.3\%) and symptomatic malaria confirmed in 87 individuals (42.6\%). Overall, individuals with detectable malaria by RDT was significantly higher in individuals with symptoms, 87 of 197 (44.2\%), than asymptomatic persons; 117 of 338 (34.6\%), $p=0.02$. In a sub-set of 75 isolates, $18(24 \%)$ and $14(18.6 \%)$ individuals had Pfmdr1 86Y and $1246 \mathrm{Y}$ mutations.

Conclusions: There is still high malaria transmission rate in Nigeria with higher incidence of asymptomatic infections. These parasites harbour mutations on Pfmdr 1 which contribute to artemisinin partner drug resistance; surveillance strategies to reduce the spread of drug resistance in endemic areas are needed to eliminate the reservoir of malaria parasites that can mitigate the eradication of malaria in Nigeria.
\end{abstract}

Keywords: Asymptomatic malaria, Pfmdr1, Drug resistance, Plasmodium falciparum, Nigeria

\section{Background}

Malaria prevalence has declined to about 216 million cases estimated in 2016 but progress in malaria reduction appears to be stagnant as reported in the World Malaria Report 2018 with the highest transmission rates still recorded in the African region [1]. Increasing drug resistance in Plasmodium falciparum in Southeast Asia and Africa now mitigates the use of some available artemisinin combination drugs for effective

\footnotetext{
*Correspondence: abiodun.adebayo@covenantuniversity.edu.ng ${ }^{1}$ Department of Biochemistry, Covenant University, Ota 23401, Nigeria Full list of author information is available at the end of the article
}

malaria eradication [1, 2]. In Nigeria, malaria transmission remains high, in South West area of Nigeria, malaria is highly endemic and transmission occurs all year round, however prevalence of malaria is often underestimated because sub-microscopic malaria is common [3]. Chemoprevention strategies for eradicating malaria, such as mass drug administration with primaquine to reduce the high reservoir of malaria infection, cannot be implemented in most malaria-endemic countries due to drug resistance and potential prevalence of glucose6-phosphate deficiency (G6PD) [3-8]. Several studies from malaria endemic countries have reported single nucleotide polymorphisms (SNPs), including K76T on 
P. falciparum chloroquine resistance transporter gene (Pfcrt); N86Y, S1034C, Y184F, N1042D, and D1246Y SNPs on multidrug resistance gene 1 (Pfmdr1) and other loci, which confers resistance to artemisinin and its partner drugs, such as chloroquine, quinine, amodiaquine, lumefantrine, and piperaquine [9-21].

Monitoring the prevalence of these molecular markers of resistance plays a significant role in assessing effective malaria chemotherapy for reducing malaria intensities. To curb the spread of drug resistance and for effective malaria control, it is necessary to study the genetic backgrounds of parasite isolates that circulate in asymptomatic infections, which are often exposed to sub-therapeutic doses of anti-malarial drugs, as these polymorphisms alter parasite susceptibility to artemisinin combination treatment (ACT) [1]. This study aims to determine frequencies of Pfmdr1 mutations in parasite isolates and intensities of asymptomatic malaria transmission in an endemic area of Nigeria.

\section{Methods}

The study was carried out in Ota, South West Nigeria to evaluate asymptomatic malaria incidence and molecular markers of anti-malarial drug resistance in $P$. falciparum. Persons aged $>6$ months, without any symptoms suggestive of malaria at the time malaria test was done and in persons reporting a history of fever within the previous 2 weeks participated in the community health screening for malaria prevalence and were included in the study which took place at intervals from April to May and November to December (both in dry and wet seasons) around communities in Ota, Ogun State in 2018. The participants gave informed consent and the study was approved by Covenant Health Research Ethics Committee (approval number: CHREC/010/2018). Parasite prevalence was determined by histidine-rich protein II-based rapid test kit. The minimum sample size required for the study was calculated as 384 , using an estimated population of 527,242 persons living in Ota and a 5\% margin of error. Molecular analysis was done at Molecular Biology
Laboratory of Covenant University. Blood from positive samples were used for PCR analysis. Genomic DNA was extracted using Aidlab Blood \& Tissue DNA mini kit according to the manufacturer's instruction and primers flanking codon 86 and 1246 of Pfmdr1 gene was used [22]. PCR amplification was done on C1000 Touch $^{\mathrm{TM}}$ Thermal Cycler (Bio-Rad Laboratories Inc., USA) using PCR super-mix (New England Biolabs, USA). Table 1 shows the details of primers and PCR conditions used. Nested PCR products were restricted by enzymatic digest with specific restriction enzymes: AflIII (New England Biolabs, USA) was used to detect mutation causing base change from asparagine $(\mathrm{N})$ to tyrosine $(\mathrm{Y})$ at codon 86 while EcoRV (Beijing TransGen Biotech, China) was used to detect mutation causing base change from aspartic acid (D) to tyrosine $(\mathrm{N})$ at codon 1246 . Enzyme was incubated at $37{ }^{\circ} \mathrm{C}$ for $1 \mathrm{~h}$ and inactivated at $65^{\circ} \mathrm{C}$ for $20 \mathrm{~min}, 10 \mu \mathrm{l}$ of the digested product was resolved on $2 \%$ agarose gel and sized against molecular weight marker. To confirm mutation, $15 \mu \mathrm{l}$ of amplicons were sent for sequencing (Inqaba Biotec West Africa Ltd, South Africa). Sequence alignment with reference 3D7 strain (PF3D7_0523000) was carried out using Geneious software ${ }^{\circledR}$ version 11.6. The data was analysed using SPSS software version 16 (SPSS Inc., Chicago, USA). Proportions were compared using Chi-square test at significant level of $\mathrm{p}<0.05$.

\section{Results}

\section{Transmission intensities}

During the study period, 535 blood samples were examined for the presence of $P$. falciparum infections by RDT. Malaria was detected in 204 (38.1\%) blood samples; 87 (42.6\%) infections in symptomatic carriers while 117 (57.3\%) persons were asymptomatic. Overall the proportion of individuals with detectable malaria by RDT (positivity rate) was significantly higher in those with symptoms (87 of $197,44.2 \%$ ) than asymptomatic persons ( 117 of $338,34.6 \%), \chi^{2}=4.80, p=0.02$. Based on age, overall malaria incidence was 7 of 49 (14.2\%), 81 of 143 (56.6\%), 60 of 195 (30.7\%) and 56 of 148 (37.85) in age

Table 1 Primer sequence of Pfmdr1 gene flanking at codon 86 and 1246

\begin{tabular}{|c|c|c|c|c|}
\hline Primer & Sequence $\left(5^{\prime} \rightarrow 3^{\prime}\right)$ & Direction & $\begin{array}{l}\text { PCR } \\
\text { product } \\
\text { (bp) }\end{array}$ & Cycling condition \\
\hline \multirow[t]{2}{*}{ Pfmdr1 86 and 184} & AGAGAAAAAAGATGGTAACCTCAG & Forward & \multirow[t]{2}{*}{590} & \multirow{2}{*}{$\begin{array}{l}95^{\circ} \mathrm{C} \text { for } 3 \mathrm{~min}, 34 \text { cycles of } 95^{\circ} \mathrm{C} \text { for } 45 \mathrm{~s}, 60.2^{\circ} \mathrm{C} \text { for } 45 \mathrm{~s} \text {, and } \\
72^{\circ} \mathrm{C} \text { for } 5 \mathrm{~min}\end{array}$} \\
\hline & ACCACAAACATAAATTAACGG & Reverse & & \\
\hline \multirow[t]{4}{*}{ Pfmdr1 1246} & GTGGAAAATCAACTTTTATGA & Forward & \multirow[t]{2}{*}{499} & \multirow{2}{*}{$\begin{array}{l}94^{\circ} \mathrm{C} \text { for } 5 \text { min, } 35 \text { cycles of } 94^{\circ} \mathrm{C} \text { for } 1 \mathrm{~min}, 53{ }^{\circ} \mathrm{C} \text { for } 1 \text { min, } 72{ }^{\circ} \mathrm{C} \\
\text { for } 1 \mathrm{~min}\end{array}$} \\
\hline & TTAGGTTCTCTTAATAATGCT & Reverse & & \\
\hline & GACTTGAAAAATGATCACATT & Forward nested & \multirow[t]{2}{*}{409} & \multirow{2}{*}{$\begin{array}{l}94^{\circ} \mathrm{C} \text { for } 5 \min , 35 \text { cycles of } 94^{\circ} \mathrm{C} \text { for } 1 \mathrm{~min}, 50^{\circ} \mathrm{C} \text { for } 1 \mathrm{~min}, 72^{\circ} \mathrm{C} \\
\text { for } 1 \mathrm{~min}\end{array}$} \\
\hline & GTCCACCTGATAAGCTTTT & Reverse nested & & \\
\hline
\end{tabular}


groups $<2,>2-10,>10-18$, and $>18$ years, respectively. Similarly, asymptomatic infection was detected in 0 of $49(0 \%), 9$ of $143(6 \%), 54$ of $195(27.6 \%)$, and 54 of 148 $(36.4 \%)$ in age groups $<2,>2-10,>10-18$, and $>18$ years, respectively. Malaria incidence was highest in children aged $>2-10$ years, however asymptomatic infection was higher in older children and adults $(\mathrm{p}<0.0001)$. There was no difference in prevalence between different genders. Of the 204 positive samples, 75 randomly selected samples were evaluated for the presence of $P f m d r 1$ mutations. Figure 1 shows the flow chart for the study.

\section{Pfmdr1 mutations}

Seventy-five positive samples selected from asymptomatic and symptomatic infections were evaluated for Pfmdr1 mutations at codons 86 and 1246. In 18 of 75 (24\%) isolates, $86 \mathrm{Y}$ alleles were detected. Similarly, 14 of $75(18.6 \%)$ isolates had $1246 \mathrm{Y}$ mutant alleles, Fig. 2 $\left(x^{2}=0.63, p=0.42\right)$. Of the total, 9 isolates $(12 \%)$ had both $86 \mathrm{Y}$ and $1246 \mathrm{Y}$ mutant alleles (Fig. 3). The proportions in asymptomatic and symptomatic infections were similar. To confirm restriction fragment length polymorphism (RFLP) digest, sequencing of few isolates with mutant $86 \mathrm{Y}$ allele aligned with 3D7 reference strain further confirms amino acid substitution from asparagine $(\mathrm{N})$ to tyrosine (Y) (Fig. 4).

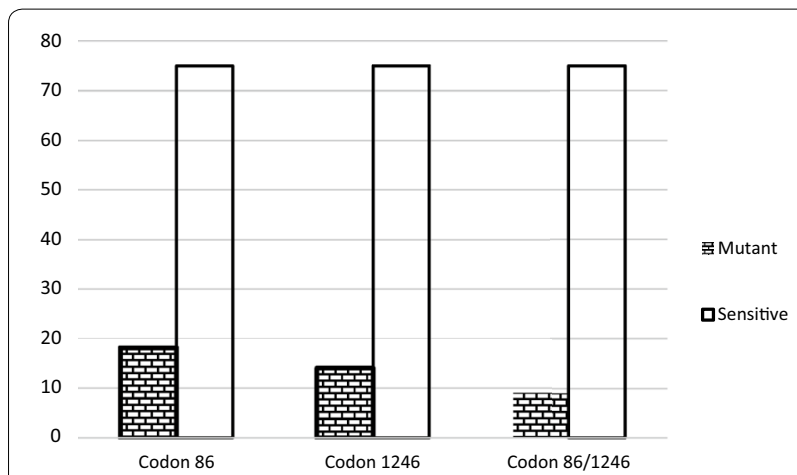

Fig. 2 Prevalence of mutant alleles detected at codon 86 (24\%) and 1246 (19\%) of Pfmdr 1 gene in parasite isolates during the study

\section{Discussion}

Malaria has persisted for several decades due to development of resistance to available anti-malarial drugs, including artemisinin derivatives and its partner drugs, and unbroken transmission in highly endemic countries $[1,2]$. To achieve malaria elimination especially in endemic areas, reducing the pool of infection by asymptomatic carriers, scaling up of control measures such as chemoprevention, vector control and monitoring of resistance for effective treatment are all essential to break transmission $[23,24]$, which has been achieved

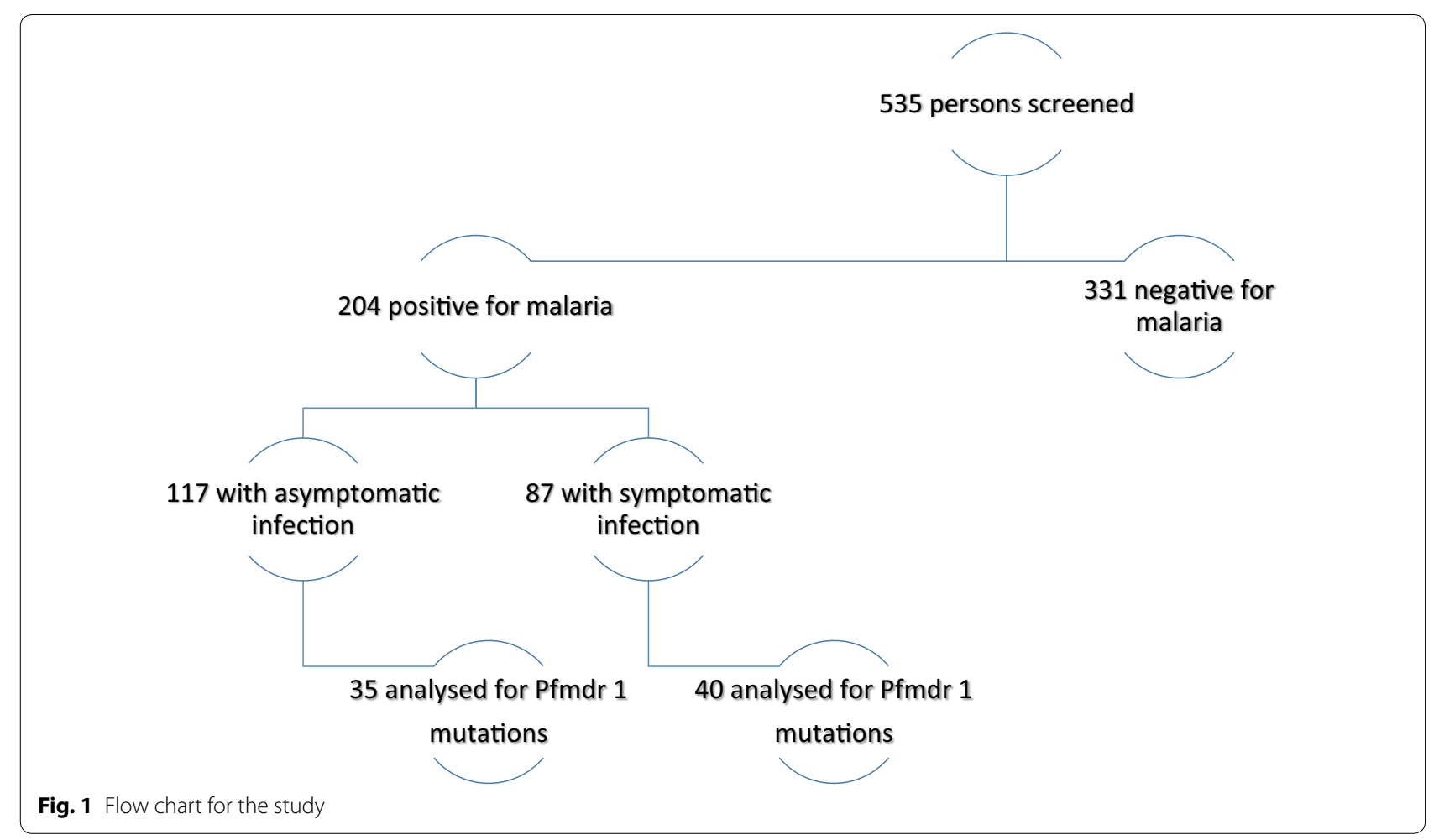




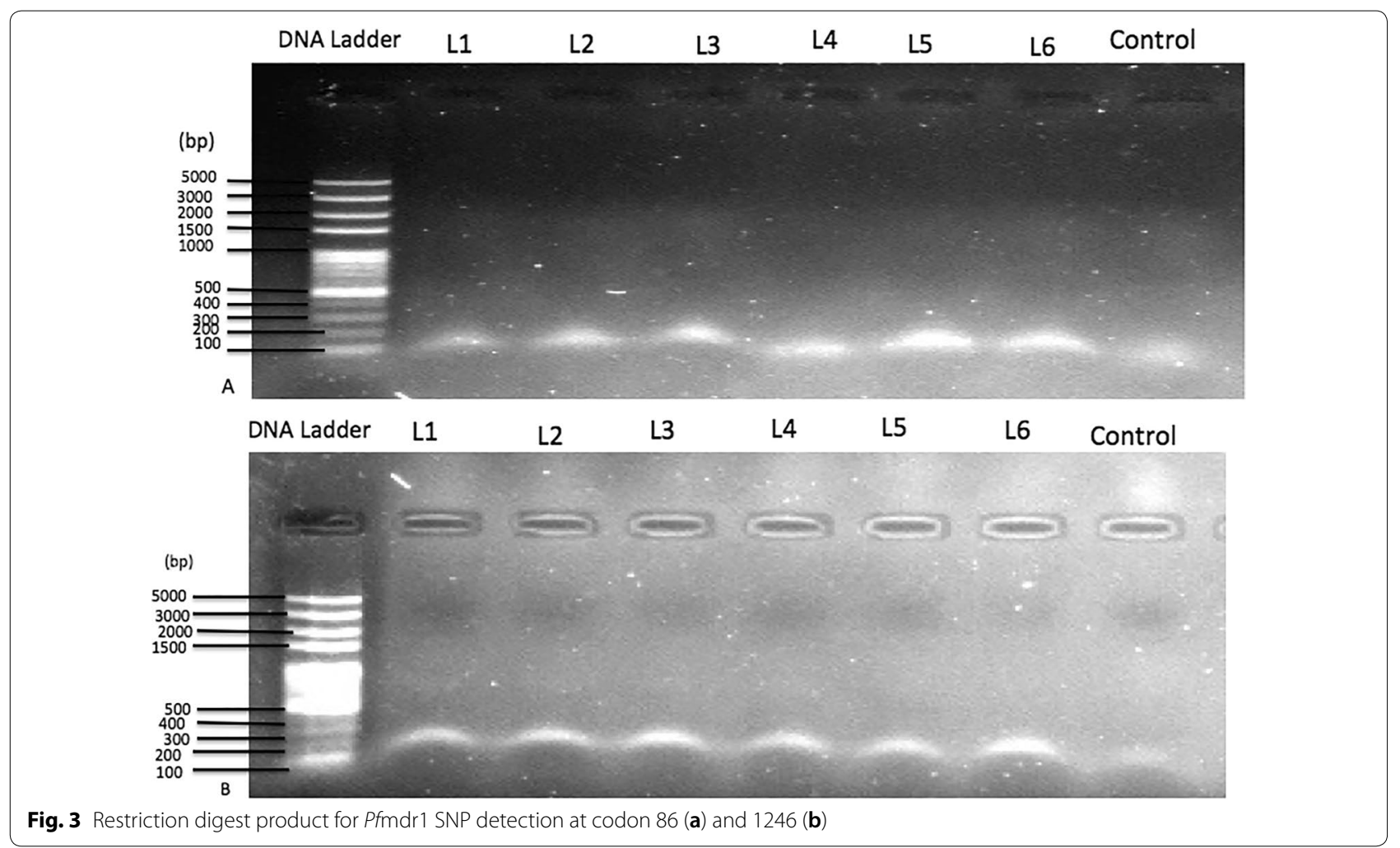

in some countries [1, 2]. World Health Organization reported stalled progress in malaria reduction from 2015 to 2017 especially from the African region. Nigeria alone contributes $25 \%$, the highest proportion borne by any single country to malaria burden globally, while other African countries, such as Democratic Republic of Congo (11\%) and Mozambique (5\%) follow [2].

Asymptomatic infection is common in endemic areas [3-7], and wide epidemiological surveys utilizing PCR are very valuable to estimate the true burden in endemic areas for planning effective malaria control strategies. Parasites isolated in untreated infections can harbour resistant genes as a tool for survival; this study reports the presence of Pfmdr1 86Y (confirmed by sequencing) and $1246 \mathrm{Y}$ mutant alleles being transmitted in asymptomatic as well as symptomatic infections. This finding is similar to reports from endemic and non-endemic areas where Pfmdr1 has served as a molecular marker of detecting anti-malarial drug resistance [13, 14, 16, 21]. Most malaria-endemic countries are in the pre-elimination phase because local transmission is still high [2]. This is largely because malaria parasites may be harboured by persons who show no symptoms; consequently, long term carriage of asymptomatic infections promotes development of committed gametocytes, and these are picked up by mosquito, increasing malaria transmission.
This cycle of asymptomatic transmission is unhindered in a country such as Nigeria because of the lack of prophylactic chemoprevention which is not encouraged due to drug resistance in the area [25]. The current study and previously reported studies clearly demonstrate that asymptomatic malaria infection is very common [3-7] in Nigeria and other endemic countries. However, clearance of these parasite reservoirs by mass drug administration using a slowly eliminated drug and tissue schizonticide such as primaquine cannot be explored because of the limitations of drug-induced haemolysis in some regions. Reflecting on prevalence of Plasmodium falciparum rates over time in Nigeria to date, it can be surmised that transmission has not significantly declined if epidemiological screenings are regularly done; a rate of $57 \%$ was detected in this study which is not similar to other recent studies [26] or previous studies in Nigeria [27-29].

With this trend in other parts of Africa [30], the agenda to eliminate malaria, which aims to completely remove and eradicate the disease locally and globally, can be achieved but through elimination of circulating parasite reservoir (infection from asymptomatic persons to mosquito and to new host), a crucial step for moving endemic countries out of the pre-elimination phase. Factors that favour intense transmission, including parasite reservoir, competent vectors and suitable breeding sites and climatic conditions, are predominant in Africa; a 


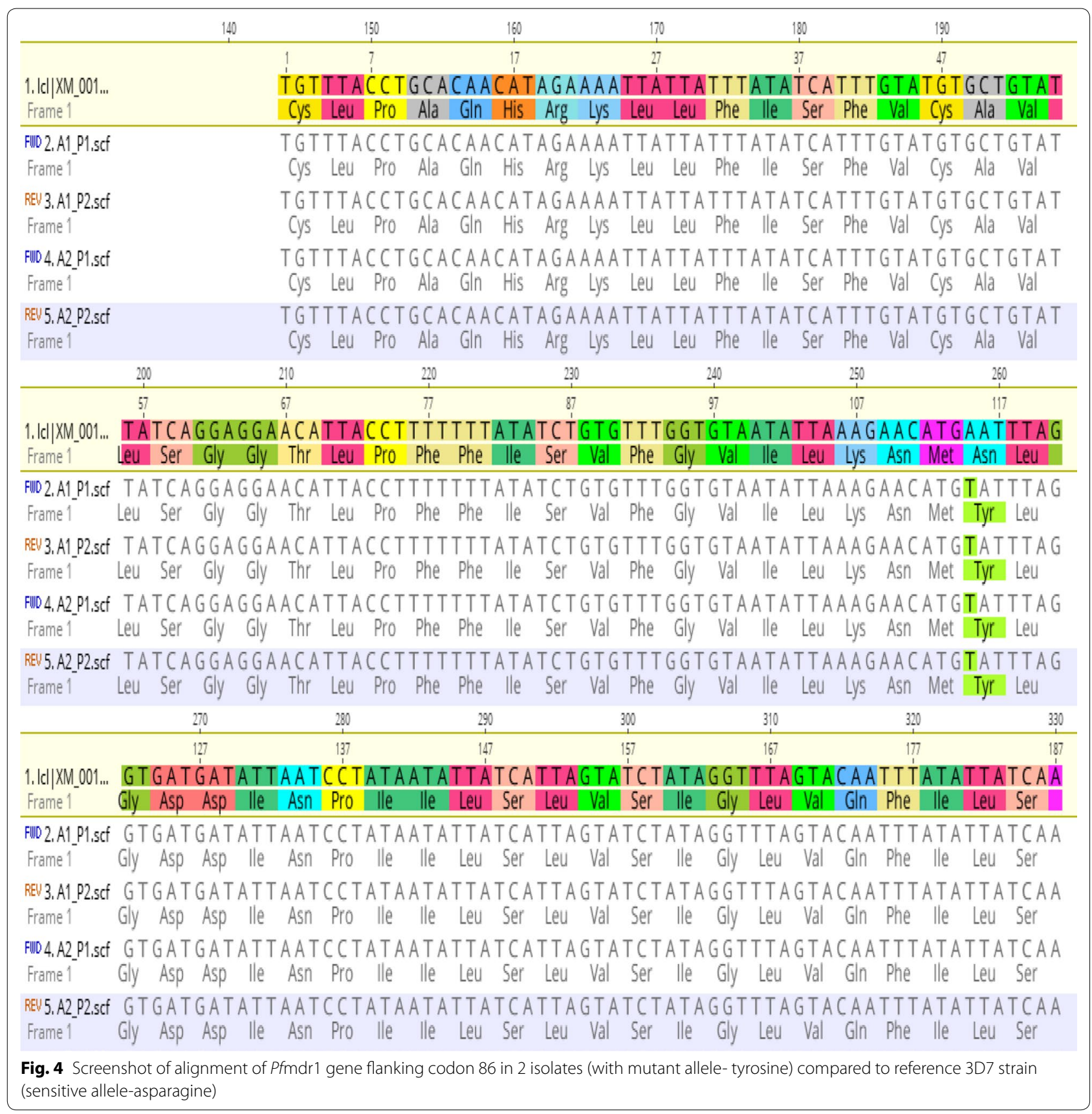

multifaceted approach to curtail transmission through all these influential factors should be promoted.

In asymptomatic infections, a similar proportion of $86 \mathrm{Y}$ and $1246 \mathrm{Y}$ mutant alleles was present as in symptomatic infections. Asymptomatic parasite tolerance is determined by the host immunity, hence the higher proportions in adults older than 18 years. Higher prevalence of these mutations conferring resistance to chloroquine, artemether, mefloquine was previously reported in Nigeria $[11,12,15,16]$, but the findings, similar to a recent study from northern Nigeria [26], indicate a decline in the prevalence of mutations. Therefore, determining the prevalence of these molecular markers can be used to assess the degree of transmission and the impact of prophylactic chemotherapy for malaria control in Nigeria.

Mutations on the $P f m d r 1$ gene play a pivotal role with variable parasite response to artemisinin, $\mathrm{ACT}$ and non$\mathrm{ACT}$, such as chloroquine, lumefantrine, primaquine, tafenoquine, piperaquine, and mefloquine [31-38], due 
to conformational changes in the transporter protein causing decrease in intracellular drug accumulation and effect on the malaria parasite.The haplotype N86YY184F-D1246Y of $P f m d r 1$ was reported to be susceptible to artemisinin-based combination, whereas triple mutations S1034C, N1042D and D1246Y or increased gene copy number are associated with parasite resistance to mefloquine, halofantrine and artemisinin [36]. Although this study did not assess Pfcrt mutation, there is known synergy between mutations on Pfmdr1 and Pfcrt genes [39]. Studies in Nigeria and other areas have reported reduced in vitro and in vivo response in chloroquineresistant isolates bearing the $76 \mathrm{~T}$ mutation correlating strongly with Pfmdr1 $86 \mathrm{Y}$ mutation [12, 14, 16, 21, 22, 38].

Although molecular markers alone may not connote resistance except resulting in drug failure, it however can predict the potential of parasites to develop drug resistance $[9,11,12]$. By implication, frequency of $P f m d r 1$ mutations observed in this area is low, but malaria incidence has not decreased significantly. Including asymptomatic malaria control using combinations not previously used [40], e.g., pyronaridine-artemisinin for chemoprophylaxis in persons with malaria infections, should be considered for Nigeria to clear out circulating asymptomatic infections for complete elimination of parasite reservoir. Evidence from the study shows one in six parasite isolates bear mutant $86 \mathrm{Y}$ and $1246 \mathrm{Y}$ alleles; eliminating these with effective drugs, together with high asymptomatic parasitaemia will greatly impact malaria eradication in this endemic area.

Limitations of this study were that microscopy, the gold standard, was not used for estimating malaria prevalence and follow-up was not done to determine if asymptomatic individuals eventually became symptomatic. Secondly, histidine-rich protein II RDTs may have detected malaria antigens in recently cleared infection, and RDTs may not detect infections at very low densities in some individuals [41, 42]. Future studies evaluating asymptomatic malaria prevalence with PCR methods are recommended.

\section{Conclusion}

There is a high malaria transmission rate in Nigeria with higher incidence of asymptomatic infections. These parasites harbour mutations on $P f m d r 1$, which contribute to artemisinin partner drug resistance; surveillance strategies to reduce the spread of drug resistance in endemic areas are needed to eliminate the reservoir of malaria parasites that can mitigate the eradication of malaria in Nigeria.

\section{Abbreviations}

ACT: artemisinin-based combination therapy; DNA: deoxyribonucleic acid; G6PD: glucose-6-phosphate dehydrogenase; PCR: polymerase chain reaction; RDT: Rapid detection kit; RFLP: restriction fragment length polymorphism; SNP: single nucleotide polymorphism.

\section{Acknowledgements}

We acknowledge all the study participants, health workers and Community Development Impact Initiative Committee for the support for this study.

\section{Authors' contributions}

All authors contributed significantly to the study: TMD designed and led the study, CUA, OFY, AOB, JOA and OA participated in the conduct and analysis, $\mathrm{EOA}, \mathrm{AHA}$ participated in the conduct, review and correction of the final manuscript. All authors read and approved the final manuscript.

\section{Funding}

This study received publication funding support from Covenant University Centre for Research, Innovation and Discovery (CUCRID), Nigeria.

Availability of data and materials

All data analysed for this study is included in the manuscript, there are no additional supporting materials.

\section{Ethics approval and consent to participate}

Ethical approval for the study was approved by Covenant Health Research Ethics Committee (approval number: CHREC/010/2018). The study participants gave consent to participate in the study.

\section{Consent for publication}

Not applicable.

\section{Competing interests}

The authors declare that they have no competing interests.

\section{Author details}

${ }^{1}$ Department of Biochemistry, Covenant University, Ota 23401, Nigeria. ${ }^{2}$ Department of Biological Sciences, Covenant University, Ota 23401, Nigeria. ${ }^{3}$ Department of Pharmacology and Therapeutics, University of Ilorin, Ilorin 24003, Nigeria. ${ }^{4}$ Demography and Social Statistics Unit, Department of Economics and Development Studies, Covenant University, Ota 23401, Nigeria.

Received: 22 February 2019 Accepted: 9 June 2019

Published online: 27 June 2019

\section{References}

1. WHO. A framework for malaria elimination. Geneva: World Health Organization; 2017. https://www.who.int/malaria/publications/atoz/97892 41511988/en/. Accessed Jan 102019.

2. WHO. World malaria report 2018. Geneva: World Health Organization 2018. https://www.who.int/malaria/publications/world-malaria-repor t-2018/en/. Accessed Jan 102019.

3. Dokunmu TM, Olasehinde GI, Oladejo DO, Olanrewaju O, Akinbobola A, Adjekukor CU, et al. Efficiency of histidine rich protein II-based rapid diagnostic tests for monitoring malaria transmission intensities in an endemic area. AIP Conf Proc. 2018;1954:030001.

4. Bousema T, Okell I, Felger I, Drakeley C. Asymptomatic malaria infections: detectability, transmissibility and public health relevance. Nat Rev Microbiol. 2014:12:833-40.

5. Lin JT, Saunders DL, Meshnick SR. The role of submicroscopic parasitemia in malaria transmission: What is the evidence? Trends Parasitol. 2014;30:183-90.

6. Lindblade KA, Steinhardt L, Samuels A, Kachur SP, Slutsker L. The silent threat: asymptomatic parasitemia and malaria transmission. Exp Rev Anti Infect Ther. 2013:11:623-39. 
7. Idris ZM, Chan CW, Kongere J, Gitaka J, Logedi J, Omar A, et al. High and heterogeneous prevalence of asymptomatic and sub-microscopic malaria infections on Islands in Lake Victoria. Kenya. Sci Rep. 2016;6:36958

8. Gunawardena S, Kapilananda GMG, Samarakoon D, Maddevithana S, Wijesundera S, Goonaratne LV, et al. Prevalence of G6PD deficiency in selected populations from two previously high malaria endemic areas of Sri Lanka. PLoS ONE. 2017;12:e0171208.

9. Ibraheem ZO, Majid RA, Noor SM, Sedik HM, Basir R. Role of different Pfcrt and pfmdr-1 mutations in conferring resistance to antimalarial drugs in Plasmodium falciparum. Malar Res Treat. 2014; doi. org/10.1155/2014/950424

10. Mita T, Tanabe K, Kita K. Spread and evolution of Plasmodium falciparum drug resistance. Parasitol Int. 2009;58:201-9.

11. Happi CT, Gbotosho GO, Folarin OA, Sowunmi A, Hudson T, O'Neil M, et al. Selection of Plasmodium falciparum multidrug resistance gene1 alleles in asexual stages and gametocytes by artemether-lumefantrine in Nigerian children with uncomplicated falciparum malaria. Antimicrob Agents Chemother. 2009;53:888-95.

12. Bustamante C, Folarin OA, Gbotosho GO, Batista CN, Mesquita EA Brindeiro RM, et al. In-vitro reduced susceptibility to artemether in $P$. falciparum and its association with polymorphisms on transporter genes. J Infect Dis. 2012;206:324-32.

13. Heuchert A, Abduselam N, Zeynudin A, Eshetu T, Löscher T, Wieser A, et al. Molecular markers of anti-malarial drug resistance in southwest Ethiopia over time : regional surveillance from 2006 to 2013. Malar J. 2015;14:208.

14. Shrivastava SK, Gupta RK, Mahanta J, Dubey ML. Correlation of molecular markers, Pfmdr1-N86Y and Pfcrt-K76T, with in vitro chloroquine resistant Plasmodium falciparum, isolated in the malaria endemic states of assam and arunachal Pradesh, Northeast India. PLoS ONE. 2014;9:e103848.

15. Oladipo OO, Wellington OA, Sutherland CJ. Persistence of chloroquineresistant haplotypes of Plasmodium falciparum in children with uncomplicated malaria in Lagos, Nigeria, four years after change of chloroquine as first-line antimalarial medicine. Diagn Pathol. 2015;10:41.

16. Olasehinde G, Ojurongbe O, Fagade E, Ruchi S, Egwari L, Ajayi A, et al. Detection of molecular markers of antimalarial drug resistance in Plasmodium falciparum from south-western Nigeria. Covenant J Phys Life Sci. 2014;1:61-766.

17. Humphrey GS, Merinopoulos I, Ahmed J, Whitty CJM, Mutabingwa TK, Sutherland CJ, et al. Amodiaquine and artemether-lumefantrine select distinct alleles of the Plasmodium falciparum mdr1 gene in Tanzanian children treated for uncomplicated malaria. Antimicrob Agents Chemother. 2007:51:991-7.

18. Somé AF, Sorgho H, Zongo I, Bazié T, Nikiéma F, Sawadogo A, et al. Polymorphism in K13, Pfmdr1, pfdhfr, and pfdhps in parasites isolated from symptomatic malaria patients in Burkina Faso. Parasite. 2016;23:60-7.

19. Njokah MJ, Kang'ethe JN, Kinyua J, Kariuki D, Kimani FT. In vitro selection of Plasmodium falciparum Pfcrt and Pfmdr1 variants by artemisinin. Malar J. 2016:15:381

20. Yang Z, Li C, Miao M, Zhang Z, Sun X, Meng H, et al. Multidrug-resistant genotypes of Plasmodium falciparum. Myanmar. Emerg Infect Dis. 2011;17:498-501.

21. Atroosh WM, Mekhlafi HM, Mahdy MAK, Surin J. The detection of Pfcrt and Pfmdr1 point mutations as molecular markers of chloroquine drug resistance, Pahang. Malaysia. Malar J. 2012;11:251.

22. Dorsey GR, Kamya MR, Singh A, Rosenthal PJ. Polymorphisms in the Plasmodium falciparumPfcrt and pfmdr-1 genes and clinical response to chloroquine in Kampala, Uganda. J Infect Dis. 2001;183:1417-20.

23. Plowe CV. Monitoring antimalarial drug resistance: Making the most of the tools at hand. J Exp Biol. 2003;206:3745-52.

24. World Health Organisation. Global technical strategy for malaria 2016-2030. Geneva:World Health Organization; 2015. https://www.who. int/malaria/publications/atoz/9789241564991/en/. Accessed 18 May 2019

25. WHO. National guidelines for the treatment of malaria. 3rd Edition. Geneva: World Health Organization; 2015. https://www.who.int/malaria/ publications/atoz/9789241549127/en/. Accessed 10 Jan 2019.
26. Muhammad RH, Nock IH, Ndams IS, George JB, Deeni Y. Distribution of Pfmdr1 and Pfcrt chloroquine drug resistance alleles in north-western Nigeria. MWJ. 2017:8:15.

27. Salako LA, Ajayi FO, Sowunmi A, Walker O. Malaria in Nigeria: a revisit. Ann Trop Med Parasitol. 1990;84:435-445.

28. Gbotosho GO, Sowunmi A, Happi CT, Okuboyejo TM. Plasmodium falciparum gametocyte carriage, sex ratios and asexual parasite rates in Nigerian children before and after a treatment protocol policy change instituting the use of artemisinin-based combination therapies. Mem Inst Oswaldo Cruz. 2011;106:685-90.

29. Olasehinde Gl, Ojurongbe DO, Akinjogunla OJ, Egwari LO, Adeyeba AO. Prevalence of malaria and predisposing factors to antimalarial drug resistance in southwestern Nigeria. Res J Parasitol. 2015;10:92-101.

30. Snow RW, Sartorius B, Kyalo D, Maina J, Amratia P, Mundia CW, et al. The prevalence of Plasmodium falciparum in sub-Saharan Africa since 1900. Nature. 2017:550:515-8.

31. Gil JP, Krishna S. Pfmdr1 (Plasmodium falciparum multidrug drug resistance gene 1): a pivotal factor in malaria resistance to artemisinin combination therapies. Expert Rev Anti Infect Ther. 2017;15:527-43.

32. Kaewpruk N, Tan-ariya P, Ward S, Sitthichot N, Suwandittakul N, Mungthin M. Pfmdr1 polymorphisms influence on in vitro sensitivity of Thai Plasmodium falciparum isolates to primaquine, sitamaquine and tafenoquine. Southeast Asian J Trop Med Public Health. 2016;47:366-76.

33. Veiga MI, Dhingra SK, Henrich PP, Straimer J, Gna N, Uhlemann A, et al. Globally prevalent Pfmdr1 mutations modulate Plasmodium falciparum susceptibility to artemisinin-based combination therapies. Nat Commun. 2016;7:11553.

34. Wurtz N, Fall B, Pascual A, Fall M, Baret E, Camara C, et al. Role of Pfmdr1 in in vitroPlasmodium falciparum susceptibility to chloroquine, quinine, monodesethylamodiaquine, mefloquine, lumefantrine, and dihydroartemisinin. Antimicrob Agents Chemother. 2014;58:7032-40.

35. Duraisingh MT, Jones P, Sambou I, von Seidlein L, Pinder M, Warhurst DC. The tyrosine-86 allele of the Pfmdr 1 gene of Plasmodium falciparum is associated with increased sensitivity to the antimalarials mefloquine and artemisinin. Mol Biochem Parasitol. 2000;108:13-23.

36. Price RN, Uhlemann AC, Brockman A, McGready R, Ashley E, Phaipun L. Mefloquine resistance in Plasmodium falciparum and increased Pfmdr 1 gene copy number. Lancet. 2004;364:438-47.

37. Mungthin M, Watanatanasup E, Sitthichot N, Suwandittakul N, Khositnithikul R, Ward SA. Influence of the Pfmdr Igene on in vitro sensitivities of piperaquine in Thai isolates of Plasmodium falciparum. Am J Trop Med Hyg. 2017:96:624-9.

38. Veiga MI, Ferreira PE, Jornhagen L. Novel polymorphisms in PlasmodiumfalciparumABC transporter genes are associated with major ACT antimalarial drug resistance. PLoS ONE. 2011;6:e20212.

39. Asare KK, Boampang JN, Duah NO, Afoakwah RS, Quashie NB. Synergism between Pfcrt and Pfmdr1 genes could account for the slow recovery of chloroquine sensitive Plasmodium falciparum strains in Ghana after chloroquine withdrawal. J Infect Public Health. 2017;10:110-9.

40. White NJ. Can new treatment developments combat resistance in malaria? Expert Opin Pharmacother. 2016;17:1303-7.

41. Forney JR, Magill AJ, Wongsrichanalai C, Sirichaisinthop J, Bautista CT, Heppner DG, et al. Malaria rapid diagnostic devices: Performance characteristics of the ParaSight F device determined in a multisite field study. J Clin Microbiol. 2001;39:2884-900.

42. Ajumobi O, Sabitu K, Nguku P, Kwaga J, Ntadom G, Gitta S, et al. Performance of an HRP-2 rapid diagnostic test in Nigerian children less than 5 years of age. Am J Trop Med Hyg. 2015;92:828-33.

\section{Publisher's Note}

Springer Nature remains neutral with regard to jurisdictional claims in published maps and institutional affiliations. 